\title{
Housing and inequalities in health
}

\section{P Howden-Chapman}

\section{Housing policies are again emerging as a key way of reducing inequalities in health}

7 ti he existence of debiltating inequalities in health across social groups has become the first law of public health. People privileged by more education, income, the dominant ethnicity, higher status jobs, and housing standards, have better health than those with less education and income, minority ethnicity, lower status jobs, and poorer housing. The elimination of these inequalities may be the public health equivalent of the search for the holy grail, but research programmes are now paying dividends by highlighting effective public policies to reduce these health inequalities. ${ }^{1-3}$

Focusing on housing and neighbourhood improvements have historically been key policy instruments to improve population health. Drawing on literature about the work environment, James Dunn in this issue links the material and psychosocial aspects of housing and neighbourhood on health in an innovative way. ${ }^{4}$ In a random telephone survey of Vancouver households he looks at several important aspects of housing. Firstly, what the house materially represents for the householders, in terms of the stream of financial services it provides-shelter from the storm and a nest egg. Secondly, the social meaning of the house to occupants-home as castle and refuge-and the relation between these factors and self reported physical and mental health.

Some of his results are predictable. Housing tenure has been associated with health in a number of studies-those who rent their houses appear to have poorer health than those who own their houses even after controlling for age, gender, and education. ${ }^{5}$ Indeed, in this survey, the combined housing variables explained the variations in health status more than educational attainment. But other results were less predictable and the pattern of results raises some intriguing contextual issues.

In most analyses of social and economic positioning, individual or household income and measures of inequality derived from it, such as the Gini coefficient, are taken as the measures of economic position. Yet wealth, though it is more difficult to measure than income, may well be more protective for health, particularly for older people, vulnerable populations in countries in rapid economic transition and in facilitating inter-generational transfers. Housing for most households is their largest monthly expediture and housing costs in the survey were related to health. But as Dunn points out, housing is also the largest capital asset most people will ever own, so that the value of a house can provide a valuable indication of a household's wealth. To measure their wealth he derived a measure of capital gain for the homeowners' properties. Although this proxy measure of wealth was not significantly related to the health status of homeowners in this survey, the clever opportunistic use of these data, which are readily available in other industrialised countries, suggests interesting comparisons could be made.

Identification with their home and the local neighbourhood showed mixed results in Dunn's survey. The psychosocial aspects of housing such as pride in a house and neighbourhood showed an association with health status only before controlling for other variables. Respondents were more likely to be in poorer health if they could not stand to be at home sometimes or they equated home with housework, which they found strainful. Not suprisingly, there were gender differences here.

Initial analysis showed that a positive identification with the neighbourhood was also related to overall good health, but in the final model it showed a reverse effect-those who lived longer in a neighbourhood felt they had worse health. The greater significance of lack of social support and self assessed stress may indicate the pressures felt from being left out, or left behind. Several multilevel studies have shown that some neighbourhoods are indeed bad for people's health. ${ }^{6}$ Maybe a change of house is a good prescription for health as a recent Swiss study suggested. ${ }^{7}$

More broadly, the role of selective migration within cities, within and across countries seems to be linked both with housing and the individual's socioeconomic position that buffers those with more resources to take risks, such as moving house. A recent British study used building society and cenus data to explore the cost of housing in the role of migration and found that there was an identifiable interaction between the housing market and housing wealth in the spatial distribution and migration of the population and consequently geographical health inequality. ${ }^{8}$

Dunn's study raises many interesting hypotheses that could be fruitfully explored in other jurisdictions. For example, he comments that the decline in infectious disease transmission has diminished the importance of housing as a point of public health intervention. This may be true in Canada, where research on income inequality points to the effectiveness of the Canadian welfare state, but this is not true of all industrialised countries. ${ }^{9}$ New Zealand, which during the 1990s had the fastest growing income inequality in the OECD, has had an associated increase in overcrowding that coincided with a devastating epidemic of meningococcal meningitis. A case-control study showed that there was an increased 10-fold risk of contracting the disease associated with living in over-crowded households. ${ }^{10}$ Consequently, a cohort study is planning to enrol all new tenants in social housing in New Zealand to monitor the impact of rehousing tenants in less crowded accommodation.

Surveys to explore new associations and intervention studies to test causal links between housing and health are important. But it is worthwhile remembering one of the limitations of any study based on householders. Many prisoners leave prison with "no fixed abode" and they are not alone in being without accommodation. ${ }^{8}$ Many cities have growing populations of homeless people. The social and economic aspects of housing, and the lack of it, continue to play an important part in generating inequalities in health.

\section{$J$ Epidemiol Community Health} 2002;56:645-646

\section{Author's affiliation}

P Howden-Chapman, Department of Public Health, Wellington School of Medicine and Health Sciences, University of Otago, PO Box 7343, Main Street, Newtown, Wellington South, New Zealand

Correspondence to: Associate Professor P Howden-Chapman; howden@wnmeds.ac.nz

\section{REFERENCES}

1 Mackenbach JP, Bakker M, eds. Inequalities in health in Europe. London: Routledge, 2002.

2 Graham $\mathrm{H}$, ed. Understanding health inequalities. 1st edn. Buckingham: Open University Press, 2001.

3 Eckersley R, Dixon J, Douglas B, eds. The social origins of health and well-being. Cambridge: Cambridge University Press, 2001. 
4 Dunn JR. Housing and inequalities in health: a study of socioeconomic dimensions of housing and self reported health from a survey of Vancouver residents. J Epidemiol

Community Health 2002;56:678-81.

5 Macintyre S, Hiscock R, Kearns A, et al.

Housing tenure and health inequalities: a

three-dimensional perspective on people,

homes and neighbourhoods. In: Graham H,

ed. Understanding health inequalities.

Buckingham: Open University

Press, 2001.
6 Diez Roux A Stein Merkin S, Arnett D, et al Neighborhood of residence and incidence of coronary heart disease. N Engl J Med 2001;345:99-106.

7 Kahlmeier S, Schindler C, Grize L, et al. Perceived environmental housing quality and wellbeing of movers. J Epidemiol Community Health 2001;55:708-15.

8 Doring $\mathbf{D}$, Shaw $M$, Brimblecome N. Housing wealth and community health: exploring the role of migration. In: Graham H, ed. Understanding health inequalities.
Buckingham: Open University Press, 2001:186-99.

9 Ross N, Wolfson M, Dunn J, et al. Relation between income inequality and mortality

in Canada and in the United States: cross sectional assessment using the census data and vital statistics. $B M$ 2000;320:898-902.

10 Baker M, McNicholas A, Garrett N, et al. Household crowding a major risk factor for meningococcal disease in Auckland children. Pediatr Infect Dis J 2000; 19:983-90.

\section{Reference linking to full text of more than 200 journals}

\section{Toll free links}

You can access the FULL TEXT of articles cited in the Journal of Epidemiology and Community Health online if the citation is to one of the more than 200 journals hosted by HighWire (http://highwire.stanford.edu) without a subscription to that journal.

There are also direct links from references to the Medline abstract for other titles.

wwww.jech.com 